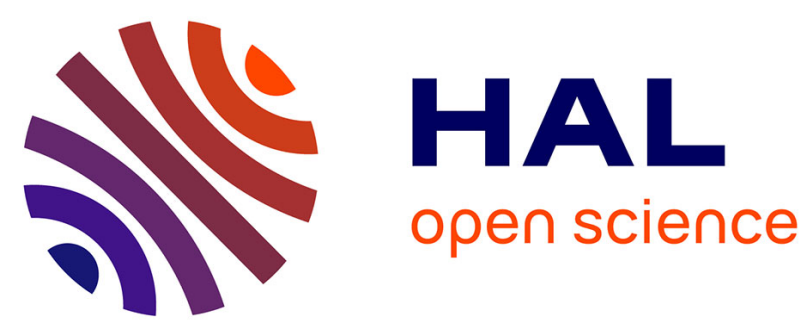

\title{
Modeling of Transport Properties Using the SAFT-VR Mie Equation of State
}

\author{
Alfonso Gonzalez, Luis Pereira, Patrice Paricaud, Christophe Coquelet, \\ Antonin Chapoy
}

\section{- To cite this version:}

Alfonso Gonzalez, Luis Pereira, Patrice Paricaud, Christophe Coquelet, Antonin Chapoy. Modeling of Transport Properties Using the SAFT-VR Mie Equation of State. SPE Annual Technical Conférence and Exhibition, Sep 2015, HOUSTON, United States. 10.2118/175051-MS . hal-01251948

HAL Id: hal-01251948

https://hal-mines-paristech.archives-ouvertes.fr/hal-01251948

Submitted on 12 Jan 2016

HAL is a multi-disciplinary open access archive for the deposit and dissemination of scientific research documents, whether they are published or not. The documents may come from teaching and research institutions in France or abroad, or from public or private research centers.
L'archive ouverte pluridisciplinaire HAL, est destinée au dépôt et à la diffusion de documents scientifiques de niveau recherche, publiés ou non, émanant des établissements d'enseignement et de recherche français ou étrangers, des laboratoires publics ou privés. 


\title{
Modeling of Transport Properties Using the SAFT-VR Mie Equation of State
} Alfonso Gonzalez, Heriot-Watt University/Mines-ParisTech PSL CTP, Luis Pereira, Heriot-Watt University, Patrice Paricaud, ENSTA-ParisTech UCP, Christophe Coquelet, Mines-ParisTech PSL CTP, and Antonin Chapoy, Heriot-Watt University

\begin{abstract}
Carbon capture and storage (CCS) has been presented as one of the most promising methods to counterbalance the $\mathrm{CO}_{2}$ emissions from the combustion of fossil fuels. Density, viscosity and interfacial tension (IFT) are, among others properties, crucial for the safe and optimum transport and storage of $\mathrm{CO}_{2}$-rich steams and they play a key role in enhanced oil recovery (EOR) operations. Therefore, in the present work the capability of a new molecular based equation of state $(E o S)$ to describe these properties was evaluated by comparing the model predictions against literature experimental data.

The EoS considered herein is based on an accurate statistical associating fluid theory with variable range interaction through Mie potentials (SAFT-VR Mie EoS). The EoS was used to describe the vapor-liquid equilibria (VLE) and the densities of selected mixtures. Phase equilibrium calculations are then used to estimate viscosity and interfacial tension values. The viscosity model considered is the TRAPP method using the single phase densities, calculated from the EoS. The IFT was evaluated by coupling this EoS with the density gradient theory of fluids interfaces (DGT). The DGT uses bulk phase properties from the mixture to readily estimate the density distribution of each component across the interface and predict interfacial tension values.

To assess the adequacy of the selected models, the modeling results were compared against experimental data of several $\mathrm{CO}_{2}$-rich systems in a wide range of conditions from the literature. The evaluated systems include five binaries $\left(\mathrm{CO}_{2} / \mathrm{O}_{2}, \mathrm{CO}_{2} / \mathrm{N}_{2}, \mathrm{CO}_{2} / \mathrm{Ar}, \mathrm{CO}_{2} / n-\mathrm{C}_{4}\right.$ and $\left.\mathrm{CO}_{2} / n-\mathrm{C}_{10}\right)$ and two multicomponent mixtures $\left(90 \% \mathrm{CO}_{2} / 5 \% \mathrm{O}_{2} / 2 \% \mathrm{Ar} / 3 \% \mathrm{~N}_{2}\right.$ and $\left.90 \% \mathrm{CO}_{2} / 6 \% n-\mathrm{C}_{4} / 4 \% n-\mathrm{C}_{10}\right)$.

The modeling results showed low absolute average deviations to the experimental viscosity and IFT data from the literature, supporting the capabilities of the adopted models for describing thermophysical properties of $\mathrm{CO}_{2}$-rich systems.
\end{abstract}

\section{Introduction}

Nowadays Carbon capture and storage (CCS) is being studied as one of the most promising process to reduce the $\mathrm{CO}_{2}$ emissions from burning fossil fuels. Several research projects have been focused in improving the safety and reducing both the costs and the environmental risks associated with CCS operations ( $\mathrm{Li}$ et al. 2011). From a thermodynamic point of view, an accurate description of thermophysical properties is crucial to the design of capture, transport and storage of $\mathrm{CO}_{2}$. Therefore, the research and the assessment of new equation of state $(\mathrm{EoS})$ models are important for the deployment of more accurate models.

In the oil and gas industry, with regard to the upstream, there is no interest in looking for more accurate EoSs, because in reservoir simulations the cubic EoSs provide enough accuracy due to uncertainties in the geology and the flow in porous media. Likewise, considering the computational time, thanks to their simplicity, cubic EoSs are scarcely replaced by more complex PVT models in reservoir simulations. However in the downstream industry and CCS, more complex thermodynamic models can be applied in order to increase the accuracy of PVT modeling: for example non-cubic EoSs can provide a better density description at high pressures and high temperatures (HPHT) (Yan et al. 2015). 
This paper focuses on one of the latest versions of the family of SAFT EoS, the SAFT-VR Mie. The adequacy of this EoS to describe transport properties like viscosity and interfacial tension (IFT), when coupled with appropriated models, has been investigated with results showing a very good agreement predictions and experimental data. The investigated systems include five binaries $\left(\mathrm{CO}_{2} / \mathrm{O}_{2}, \mathrm{CO}_{2} / \mathrm{N}_{2}\right.$, $\mathrm{CO}_{2} / \mathrm{Ar}, \mathrm{CO}_{2} / n-\mathrm{C}_{4}$ and $\left.\mathrm{CO}_{2} / n-\mathrm{C}_{10}\right)$ and two multicomponent mixtures $\left(90 \% \mathrm{CO}_{2} / 5 \% \mathrm{O}_{2} / 2 \% \mathrm{Ar} / 3 \% \mathrm{~N}_{2}\right.$ and $\left.90 \% \mathrm{CO}_{2} / 6 \% n-\mathrm{C}_{4} / 4 \% n-\mathrm{C}_{10}\right)$ in a wide range of pressure and temperature conditions.

\section{Model Description}

\section{Equation of state}

The SAFT-VR Mie EoS proposed by Lafitte et al. 2013 is one of the latest versions of the SAFT equations of state. The SAFT-VR Mie is featured by the use of the Mie potential to describe the attraction-repulsion interactions between the segments which build the molecules. The Mie potential is defined as:

$u^{M i e}(r)=\frac{\lambda_{r}}{\lambda_{r}-\lambda_{a}}\left(\frac{\lambda_{r}}{\lambda_{a}}\right)^{\frac{\lambda_{r}}{\lambda_{r}-\lambda_{a}}} \varepsilon\left(\left(\frac{\sigma}{r}\right)^{\lambda_{r}}-\left(\frac{\sigma}{r}\right)^{\lambda_{a}}\right)$

where $r$ is radial distance, $\sigma$ the temperature-independent segment diameter, $\varepsilon$ the potential depth; $\lambda_{r}$ and $\lambda_{a}$ are the repulsive and attractive ranges, respectively. The Mie parameters for the substances studied in this work are reported in the Table 1.

Table 1: Molecular parameters of the compounds used in this work (Lafitte et al. 2013)

\begin{tabular}{lccccc}
\hline Substance & $m_{s}$ & $\sigma / \AA$ & $(\varepsilon / k) / K$ & $\lambda_{r}$ & $\lambda_{a}$ \\
\hline Carbon dioxide & 1.5000 & 3.1916 & 231.88 & 27.557 & 5.1646 \\
n-butane & 1.8514 & 4.0887 & 273.64 & 13.650 & 6 \\
n-decane & 2.9976 & 4.5890 & 400.79 & 18.885 & 6 \\
Nitrogen & 1.4214 & 3.1760 & 72.438 & 9.8749 & 6 \\
Oxygen & 1.4283 & 2.9671 & 81.476 & 8.9218 & 6 \\
Argon & 1.0000 & 3.4038 & 117.84 & 12.085 & 6 \\
\hline
\end{tabular}

The SAFT-VR Mie EoS can be expressed in terms of the reduced Helmholtz energy as the summation of several contributions:

$a=\frac{A}{N k T}=a^{I D E A L}+a^{M O N O}+a^{C H A I N}+a^{A S S O C}$

where $a^{I D E A L}$ is the ideal gas contribution, $a^{\text {MONO }}$ the monomer contribution, $a^{\text {CHAIN }}$ the contribution due to chain formation and $a^{A S S O C}$ the association contribution. The expressions of each contribution can be found in the studies of Lafitte et al. 2013.

Regarding to the phase equilibria, the thermodynamic criterion for phase equilibrium is the equality of chemical potentials of each component in all co-existing phases. Using the SAFT EoS, the chemical potential can be derived as $\mu=(\partial A / \partial N)_{V, T}$ and then used to calculate the fugacity of each component (Chapoy et al. 2013). In addition to the pure molecular parameters, temperature independent binary interaction parameters $k_{i j}$ have been adjusted against solubility data (database Knapp et al. 1982) to improve the description of vapor-liquid equilibria. The optimum $k_{i j}$ parameters used in Eq. 3 are reported in Table 2. The VLE predictions using SAFT-VR Mie with the adjusted $k_{i j}$ are presented in the Fig. 1. The percentage absolute average deviation (\%AAD) between the predicted saturation pressure 
and vapor composition and experimental data of Nagarajan are $2.8 \%$ Psat and $0.9 \%$.

$\varepsilon_{i j}=\left(1-k_{i j}\right) \frac{\sqrt{\sigma_{i}^{3} \sigma_{j}^{3}}}{\sigma_{i j}^{3}} \sqrt{\varepsilon_{i} \varepsilon_{j}}$

Table 2: Binary interaction parameters between $\mathrm{O}_{2}, \mathrm{Ar}, \mathrm{N}_{2}$ and $\mathrm{CO}_{2}$, and between $\mathrm{CO}_{2}, n$-butane and $n$ decane for the SAFT-VR Mie used in this work.

\begin{tabular}{l|llllll}
\hline \multicolumn{1}{c}{} & $\mathrm{N}_{2}$ & $\mathrm{O}_{2}$ & $\mathrm{Ar}$ & $\mathrm{CO}_{2}$ & $n-\mathrm{C}_{4}$ & $n-\mathrm{C}_{10}$ \\
\cline { 2 - 7 } $\mathrm{N}_{2}$ & 0 & -0.009 & -0.017 & -0.127 & - & - \\
$\mathrm{O}_{2}$ & -0.009 & 0 & -0.023 & -0.033 & - & - \\
$\mathrm{Ar}$ & -0.017 & -0.023 & 0 & -0.014 & - & - \\
$\mathrm{CO}_{2}$ & -0.127 & -0.033 & -0.014 & 0 & 0.053 & 0.057 \\
$n-\mathrm{C}_{4}$ & - & - & - & 0.053 & 0 & -0.004 \\
$n-\mathrm{C}_{10}$ & - & - & - & 0.057 & -0.004 & 0 \\
\hline
\end{tabular}

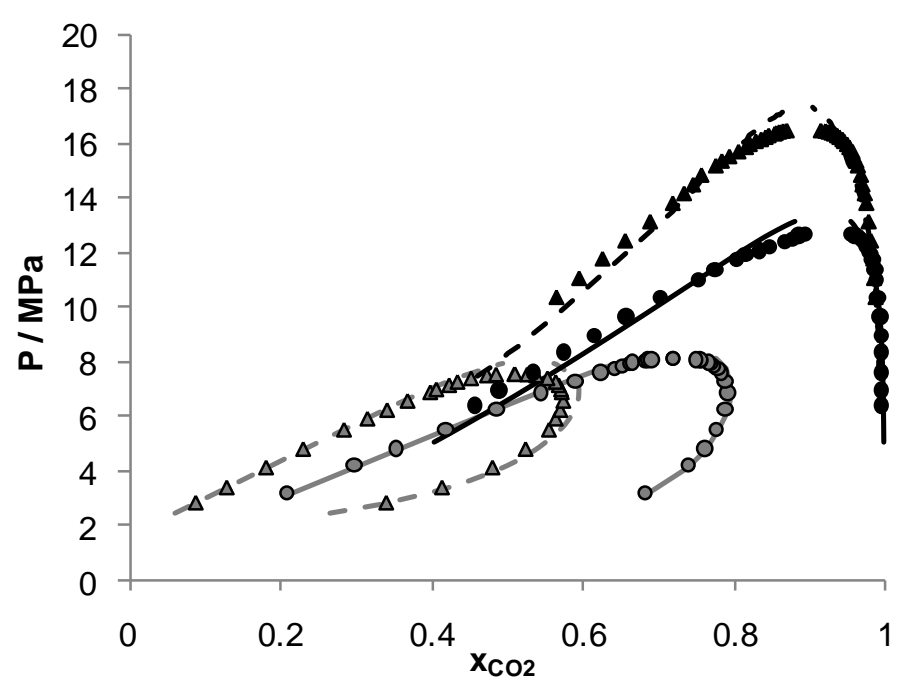

Fig. 1: Predicted VLE by SAFT-VR Mie for $\mathrm{CO}_{2}-n \mathrm{C}_{4}$ (grey) (Nagarajan 1985) and $\mathrm{CO}_{2}-n \mathrm{C}_{10}$ (black) (Nagarajan 1986). Symbols: $(\bullet) \mathrm{T}=344.3$ and $(\triangle) \mathrm{T}=377.6 \mathrm{~K}$.

\section{Viscosity model}

TRAPP (TRAnsport Properties Prediction) is a predictive model based on the extended corresponding states theory (ECS) (K. C. M. and K. E. Gubbins 1976; Hanley and Cohen 1976), used to estimate the viscosity and thermal conductivity of pure fluids and their mixtures over the entire phase range. In the original TRAPP, propane was employed as reference fluid (Ely and Hanley 1983), although several reference fluids can be selected (Huber et. 1992). Accordingly, the residual viscosity of the mixture at a corresponding state point $\left(\mathrm{T}_{0}\right.$ and $\left.\rho_{0}\right)$ is given by:

$$
\Delta \eta(\rho, T)=\eta_{m}-\eta_{m}^{0}=F_{\eta m}\left[\eta_{R}-\eta_{R}^{0}\right]+\Delta \eta^{E N S K O G}
$$

where $\eta_{m}{ }^{0}$ is the viscosity of the mixture at low pressure evaluated by Herning and Zipperer (1936) approximation. The term $\eta_{R}-\eta_{R}{ }^{0}$ is the residual viscosity of the reference fluid which is calculated as (Younglove and Ely 1987): 


$$
\eta_{R}-\eta_{R}^{0}=G_{1} \exp \left[\rho_{0}^{0.1} G_{2}+\rho_{0}^{0.5}\left(\rho_{r, R}-1\right) G_{3}\right]-G_{1}
$$

where $\eta_{R}$ is the real viscosity at $T_{0}$ and $\rho_{0}$ of the reference fluid, $\eta_{R}{ }^{0}$ is the viscosity at low pressure and $T_{0}$, and $\rho_{r, R}$ is the reduced density calculated as $\rho_{r, R}=\rho_{0} / \rho_{c, R}$. The corresponding state $\left(T_{0}\right.$ and $\left.\rho_{0}\right)$ is calculated as $T_{0}=T / f_{m}$ and $\rho_{0}=\rho h_{m} . G_{1}, G_{2}$ and $G_{3}$ are parameters that can be calculated as:

$$
\begin{aligned}
& G_{1}=\exp \left(E_{1}+E_{2} / T\right) \\
& G_{2}=E_{3}+E_{4} / T^{1.5} \\
& G_{3}=E_{5}+E_{6} / T+E_{7} / T^{2}
\end{aligned}
$$

where the $E_{i}$ parameters have been correlated for propane as reference fluid and are shown in Table 3.

Table 3: $E_{i}$ parameter TRAPP Model (Poling et al. 2001).

$\begin{array}{ll}E_{1} & -14.113294896 \\ E_{2} & 968.22940153 \\ E_{3} & 13.686545032 \\ E_{4} & -12511.628378 \\ E_{5} & 0.01168910864 \\ E_{6} & 43.527109444 \\ E_{7} & 7659.4543472\end{array}$

In order to calculate the terms $F_{\eta m}$ and $\Delta \eta^{\text {ENSKOG }}$, the following mixing rules were applied:

$$
\begin{aligned}
& h_{m}=\sum_{i} \sum_{j} y_{i} y_{j} h_{i j} \\
& f_{m} h_{m}=\sum_{i} \sum_{j} y_{i} y_{j} h_{i j} f_{i j} \\
& h_{i j}=\frac{\left(\left(h_{i}\right)^{1 / 3}+\left(h_{j}\right)^{1 / 3}\right)}{8} \\
& f_{i j}=\left(f_{i} f_{j}\right)^{1 / 2}
\end{aligned}
$$

where $y_{i}$ is the mole fraction of component $i ; f_{i}$ and $h_{i}$ are functions of the critical parameters and acentric factor defined as:

$$
\begin{aligned}
& f_{i}=\frac{T_{C}}{T_{C}^{R}}\left[1+\left(\omega-\omega^{R}\right)\left(0.05203-0.7498 \ln T_{r}\right)\right] \\
& h_{i}=\frac{\rho_{C}^{R}}{\rho_{C}} \frac{Z_{C}^{R}}{Z_{C}}\left[1+\left(\omega-\omega^{R}\right)\left(0.1436-0.2822 \ln T_{r}\right)\right]
\end{aligned}
$$

The viscosity dimensional scaling factor can be calculated as: 


$$
F_{\eta m}=\left(M_{R}\right)^{-1 / 2}\left(h_{m}\right)^{-2} \sum_{i} \sum_{j} y_{i} y_{j}\left(f_{i j} M_{i j}\right)^{1 / 2}\left(h_{i j}\right)^{4 / 3}
$$

with

$$
M_{i j}=\frac{2 M_{i} M_{j}}{M_{i}+M_{j}}
$$

where $M_{i}$ denotes the molecular weight.

The expression $\Delta \eta^{E N S K O G}$ is the residual viscosity which takes into account the differences in the molecules size based on the hard sphere assumption (Poling et al. 2001):

$$
\Delta \eta^{\text {ENSKOG }}=\eta_{m}^{E N S K O G}-\eta_{x}^{E N S K O G}
$$

with

$$
\eta_{m}^{E N S K O G}=\alpha \rho^{2} \sum_{i} \sum_{j} y_{i} y_{j} \sigma_{i j}^{6} \eta_{i j}^{0} g_{i j}^{h s}+\sum_{i} \beta_{i} Y_{i}
$$

where the $\alpha$ parameter is $\alpha=9.725 \times 10^{-7}$ and $\sigma_{i}$ is the hard-sphere diameter calculated as $\sigma_{i}=4.771 h_{i}^{1 / 3}$. The radial distribution function of the hard-sphere fluid is given by the following equation (Gubbins and Gray 1972):

$$
g_{i j}^{h s}=\frac{1}{(1-\xi)}+\frac{3 \xi}{(1-\xi)^{2}} \Phi_{i j}+\frac{2 \xi^{2}}{(1-\xi)^{3}} \Phi_{i j}^{2}
$$

where

$$
\begin{aligned}
& \Phi_{i j}=\frac{\sigma_{i} \sigma_{j}}{2 \sigma_{i j}} \frac{\sum_{k} y_{k} \sigma_{k}^{2}}{\sum_{k} y_{k} \sigma_{k}^{3}} \\
& \xi=\frac{\pi}{6} \rho \sum_{k} y_{k} \sigma_{k}^{3}
\end{aligned}
$$

To calculate the expression $\Sigma \beta_{i} Y_{i}$ it is necessary to solve the linear system of equations of the form:

$$
\sum_{i} B_{i j} \beta_{i}=Y_{i}
$$

with

$$
\begin{aligned}
& Y_{i}=y_{i}\left[1+\frac{18 \pi}{15} \rho \sum_{j} y_{j} \frac{M_{j}}{M_{i}+M_{j}} \sigma_{i j}^{3} g_{i j}^{h s}\right] \\
& B_{i j}=2 \sum_{k} y_{i} y_{k} \frac{g_{i k}}{\eta_{i k}^{0}}\left(\frac{M_{k}}{M_{i}+M_{k}}\right)^{2}\left[\left(1+\frac{5 M_{i}}{3 M_{k}}\right) \delta_{i j}-\frac{2 M_{i}}{3 M_{k}} \delta_{j k}\right]
\end{aligned}
$$

where $\delta_{i j}$ is the Kronecker function which is a delta function (i.e., $\delta_{i j}=1 \mathrm{if} \mathrm{i}=\mathrm{j}$ and $\delta_{i j}=0$ in other cases).

\section{Interfacial tension model}

The density gradient theory (DGT) has been used to compute the interfacial tension. This model is based 
on the square gradient of van der Waals (Rowlinson 1979) and on the reformulation of Cahn and Hilliard 1958 to compute interfacial tension values from bulk phase properties such as density and composition. The DGT, when coupled with appropriate thermodynamic models, has been successfully applied in the prediction of interfacial properties of a wide class of systems and interfaces. The reader is referred to the study of Pereira et al. (2015) and references within for more details. In this work, the SAFT-VR Mie EoS was used to estimate the bulk equilibrium of the investigated systems and DGT used to predict interfacial properties. The main equations within the DGT framework are given below.

In summary, by applying the minimization criterion of the Helmholtz energy to planar interfaces, the interfacial tension values with respects to the density of a reference component is given by Miqueu et al. 2004 and 2005:

$$
I F T=\int_{\rho_{r e f}^{V}}^{\rho_{\text {ref }}^{L}} \sqrt{2 \Delta \Omega(\rho) \sum_{i} \sum_{j} c_{i j} \frac{d \rho_{i}}{d \rho_{\text {ref }}} \frac{d \rho_{j}}{d \rho_{\text {ref }}} d \rho_{\text {ref }}}
$$

where $\rho^{L}{ }_{r e f}$ and $\rho^{V}{ }_{r e f}$ are the bulk phase densities and the ref subscript denotes the reference component of the mixture. $\Delta \Omega$ is the variation of the grand thermodynamic potential which is related to the Helmholtz free energy by the following equation:

$$
\Delta \Omega=f_{0}(\rho)-\sum_{i} \rho_{i} \mu_{i}+p
$$

where $f_{0}$ is the Helmholtz free energy density of the homogeneous fluid at local density, $\mu_{i}$ are the chemical potential of each component and $p$ is the pressure at equilibrium. The methodology described by Miqueu et al. 2004 was here followed for determining the density distribution of each component across the interface.

In Eq. 25, $c_{i j}$ is the cross influence parameter and the mixing rule used based on the geometric mean of the pure component influence parameters (Carey 1979) and it is given by

$$
c_{i j}=\left(1+\beta_{i j}\right) \sqrt{c_{i} c_{j}}
$$

where $\beta_{i j}$ is the binary interaction parameter and $c_{i}$ and $c_{j}$ are the pure component influence parameters. In this work, the binary parameter $\beta_{i j}$ has been fixed to 0 , making the calculation of the interfacial tension of the systems investigated fully predictive. The influence parameters $c_{i}$ and $c_{j}$ can be derived from theoretical expressions (Freeman and McDonald 1973). Nevertheless, the parameters are generally correlated using Surface Tension (ST) data from pure substances, by rewriting Eq. 25 for $c_{i}$ as follows:

$$
c_{i}=\frac{1}{2}\left[\frac{S T}{\int_{\rho^{V}}^{\rho^{L}} \sqrt{f_{0}-\rho \mu+p} d \rho}\right]^{2}
$$

There are different approaches for calculating the influence parameters of each pure component (Miqueu et al. 2004). In this work, $c_{i}$ has been taken as a constant value calculated from ST data far from the critical point (Lafitte et al. 2010). Hence, the influence parameters used were adjusted against ST data (NIST webbook 2013) of the pure components at a reduced temperature $t_{r}=0.7$. The parameters used are reported in Table 4.

Table 4: Density gradient theory influence parameters used in Eq. 26. 


\begin{tabular}{ll}
$\mathrm{CO}_{2}$ & $2.37 \times 10^{-20}$ \\
$n$-butane & $1.68 \times 10^{-19}$ \\
$n$-decane & $9.51 \times 10^{-19}$ \\
\hline
\end{tabular}

\section{Results}

\section{Viscosity}

The viscosity of $\mathrm{CO}_{2}$ systems was calculated using the TRAPP model and the densities computed from the SAFT-VR Mie EoS. A literature review of the available experimental data on the viscosity of some mixtures of relevance for CCS operations was carried and the results listed in Table $\mathbf{5}$. As can be seen in Table 5, experimental data on this property are available in a broad range of temperatures but, in most studies, pressure is limited to either atmospheric pressure or to a maximum pressure of 2.6MPa. Only in the study of Chapoy et al. 2013 this property has been investigated for temperatures in the range (273$423) \mathrm{K}$ and pressures up to $150 \mathrm{MPa}$. The viscosity studies were conducted in the single phase region, i.e. Gas (G) phase at low pressures, Liquid (L) above saturation pressure or in the supercritical (SC) region, as described in Table 5.

Table 5: Literature experimental data for the viscosity of $\mathrm{CO}_{2}$-mixtures with $\mathrm{N}_{2}, \mathrm{O}_{2}$, and $\mathrm{Ar}$.

\begin{tabular}{|c|c|c|c|c|c|c|}
\hline Source & System & Phase & $\mathbf{T} / \mathbf{K}$ & $\mathrm{P} / \mathrm{MPa}$ & $\mathbf{N}$ & Uncertainty \\
\hline Kestin and Leidenfrost (1959) & $\mathrm{CO}_{2} / \mathrm{N}_{2}, \mathrm{CO}_{2} / \mathrm{N}_{2}$ & G & 293 & $0.1-2.17$ & 28 & $\pm 0.05 \%$ \\
\hline Kestin et al. (1966) & $\mathrm{CO}_{2} / \mathrm{N}_{2}, \mathrm{CO}_{2} / \mathrm{Ar}$ & G & 293-304 & $0.1-2.6$ & 83 & $\pm 0.1 \%$ \\
\hline Gururaja et al. (1967) & $\mathrm{CO}_{2} / \mathrm{N}_{2}, \mathrm{CO}_{2} / \mathrm{O}_{2}$ & $\mathrm{G}$ & 298 & 0.1 & 17 & \\
\hline Kestin and Ro (1974) & $\mathrm{CO}_{2} / \mathrm{N}_{2}, \mathrm{CO}_{2} / \mathrm{Ar}, \mathrm{CO}_{2} / \mathrm{N}_{2} / \mathrm{Ar}$ & $\mathrm{G}$ & $297-773$ & 0.1 & 64 & $\pm 0.15 \%$ \\
\hline Kestin et al. (1977) & $\mathrm{CO}_{2} / \mathrm{O}_{2}$ & $\mathrm{G}$ & $298-674$ & 0.1 & 10 & $\pm 0.3 \%$ \\
\hline Hobley et al. (1989) & $\mathrm{CO}_{2} / \mathrm{Ar}$ & $\mathrm{G}$ & $301-521$ & 0.1 & 24 & $<0.7 \%$ \\
\hline \multirow[t]{2}{*}{ Chapoy et al. (2013) } & $\mathrm{CO}_{2} / \mathrm{N}_{2} / \mathrm{O}_{2} / \mathrm{Ar}$ & $\mathrm{G} / \mathrm{L} / \mathrm{SC}$ & $273-423$ & $1.5-150$ & 38 & \\
\hline & & & & Total & 264 & \\
\hline
\end{tabular}

The modeling results for the viscosity of the $\mathrm{CO}_{2}$-rich systems are shown in Table 6, along with the percentage absolute average deviation (\%AAD) between predicted and experimental viscosity values for each studied system. A total of 264 experimental points were considered and an overall \%AAD of 2.68 $\%$ was calculated for the viscosity values predicted with the TRAPP+SAFT-VR Mie model. This value represents half of the deviation reported by Huber (1996) and Poling et al. (2001) and obtained with the TRAPP model combined with a modified BWR-EoS. Nonetheless, the largest deviations with the TRAPP+SAFT-VR Mie model were obtained at high pressures and low temperatures, as depicted in Fig. 2, with a maximum deviation of $9.3 \%$ for the multicomponent system $\left(90 \% \mathrm{CO}_{2}, 5 \% \mathrm{O}_{2}, 2 \% \mathrm{Ar}\right.$ and $\left.3 \% \mathrm{~N}_{2}\right)$.

Table 6: Absolute average deviation of the viscosity calculations.

\begin{tabular}{llllll}
\hline System & $\mathrm{x}_{\mathrm{CO} 2}$ & $\mathrm{~N}$ & $\mathrm{~T} / \mathrm{K}$ & $\mathrm{P} / \mathrm{MPa}$ & $\% \mathrm{AAD}$ \\
\hline $\mathrm{CO}_{2} / \mathrm{N}_{2}$ & $0.19-0.90$ & 95 & $293-773$ & $0.1-2.6$ & 3,12 \\
$\mathrm{CO}_{2} / \mathrm{Ar}$ & $0.22-0.92$ & 96 & $293-773$ & $0.1-2.6$ & 1,28 \\
$\mathrm{CO}_{2} / \mathrm{O}_{2}$ & $0.19-0.92$ & 19 & $298-674$ & 0.1 & 3,25
\end{tabular}




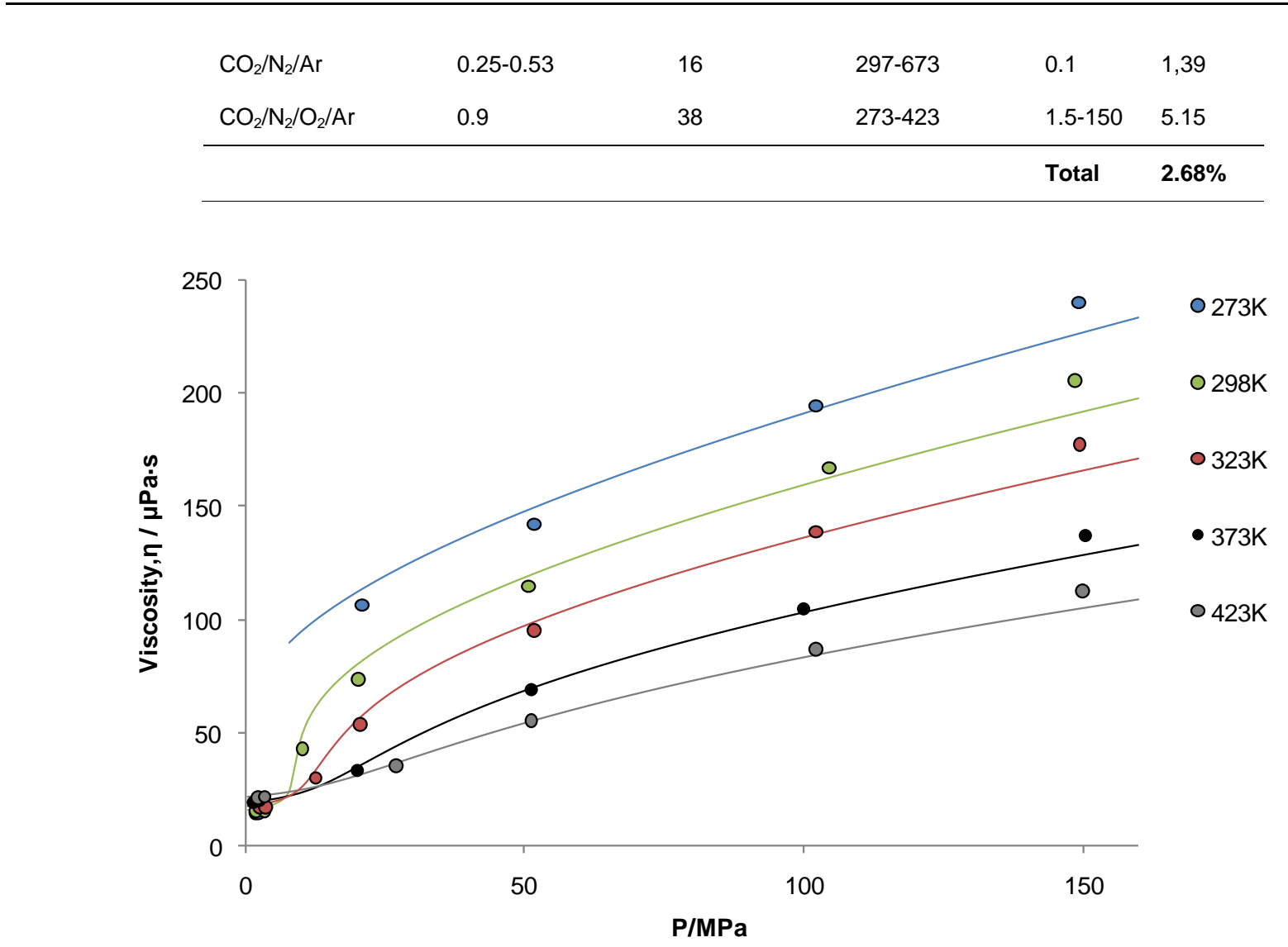

Fig. 2: Experimental (Chapoy et al. 2013) and predicted viscosity of a $\mathrm{CO}_{2}$-rich system $\left(90 \% \mathrm{CO}_{2}, 5 \% \mathrm{O}_{2}, 2 \% \mathrm{Ar}\right.$ and $\left.3 \% \mathrm{~N}_{2}\right)$.

\section{Interfacial tension}

The saturated densities and IFT of $\mathrm{CO}_{2}$-rich systems were modeled by coupling the DGT with the SAFT-VR Mie EoS. The results for the binaries $\mathrm{CO}_{2}-n-\mathrm{C}_{4}$ and $\mathrm{CO}_{2}-n-\mathrm{C}_{10}$ and the ternary $\mathrm{CO}_{2}-n-\mathrm{C}_{4}-n-$ $\mathrm{C}_{10}$ are plotted in Fig. 3 and Fig. 4, respectively. As can be seen in Fig. 3 and Fig. 4, the DGT+SAFTVR Mie predictions are in excellent agreement with the measured saturated density and IFT data of the systems considered. Largest deviations were observed close to the critical point, where the SAFT-VR Mie fails to capture the impact of pressure on the density of the bulk phases. Nonetheless, as can be seen in Figure 5, the maximum absolute deviation between predicted and measured IFT data was of $0.26 \mathrm{mNm}^{-1}$. In general, the IFT values for the $\mathrm{CO}_{2}-n-\mathrm{C}_{4}$ system and the ternary system are slightly overestimated, whereas an inverse behavior was observed for the $\mathrm{CO}_{2}-n-\mathrm{C}_{10}$ system. 

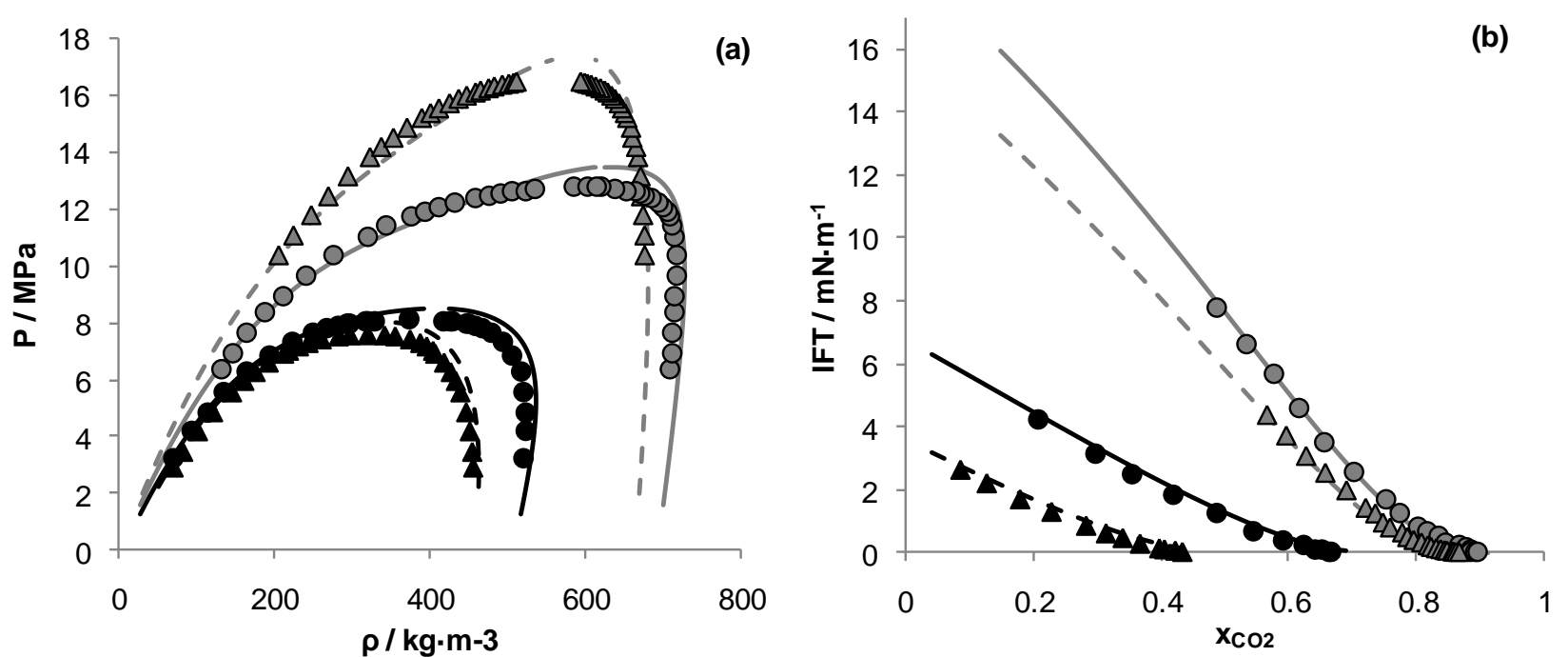

Fig. 3: Predicted density (a) and IFT (b) of $\mathrm{CO}_{2}-n C_{4}$ (black) (Nagarajan 1985) [ref] and $\mathrm{CO}_{2}-n \mathrm{C}_{10}$ (grey) (Nagarajan 1986). Symbols: $(\bullet) \mathrm{T}=344.3$ and $(\Delta) \mathrm{T}=377.6 \mathrm{~K}$.
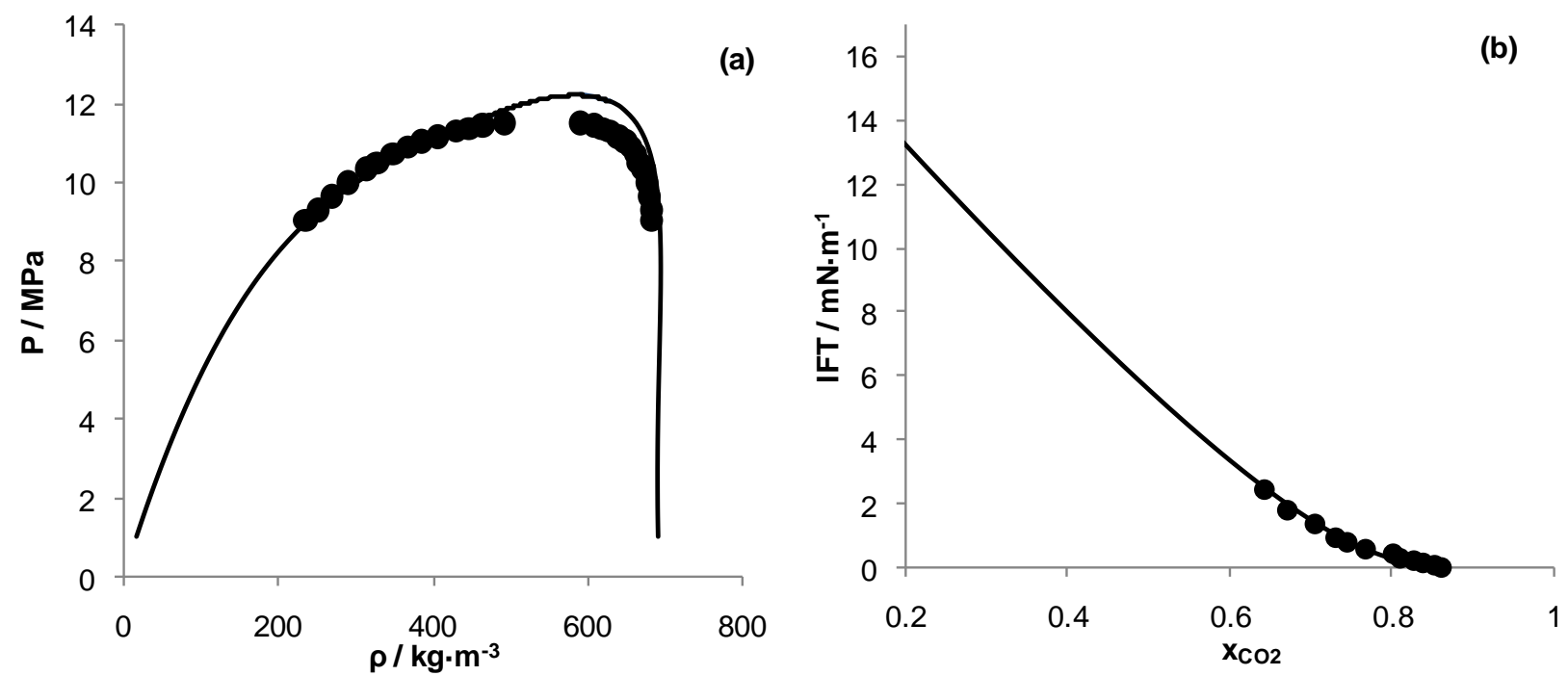

Figure 4: Predicted density (a) and IFT (b) of $\mathrm{CO}_{2}-n \mathrm{C}_{4}-n \mathrm{C}_{10}$ mixture at 344.3K (Nagarajan 1990).

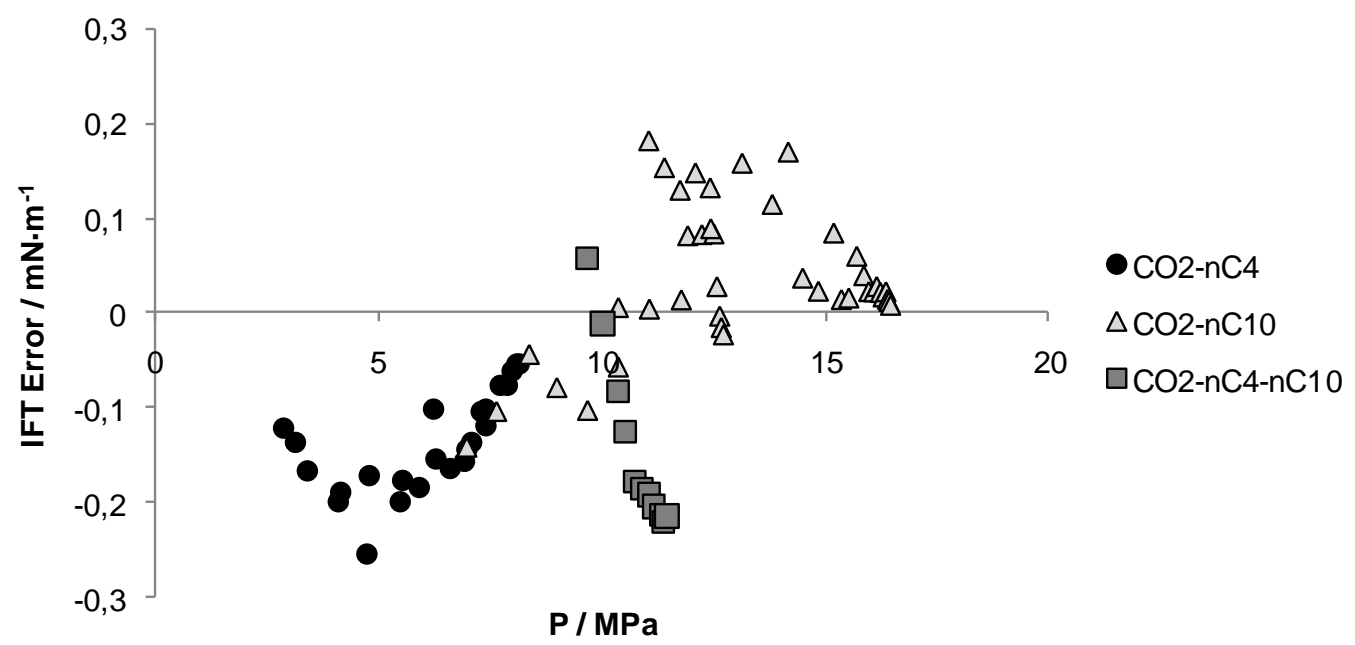

Fig. 5: Absolute deviation between prediction and experimental IFT data (IFTerror=IFT ${ }^{\mathrm{EXP}}-\mathrm{IFT}^{\mathrm{CALC}}$ ). 
In addition, the density profiles through the interface were computed with the DGT approach for the ternary system $\left(90 \% \mathrm{CO}_{2}, 6 \%\right.$-butane and $4 \%$-decane) and the results plotted in Fig. 5. As depicted in Fig. 5(a), the density profiles show a local enrichment of the interface with $\mathrm{CO}_{2}$ molecules as a peak was noticeable in the density profile of carbon dioxide. The location of peak closer to the vapor side of the interface suggests that the absorption of $\mathrm{CO}_{2}$ occurred at the surface of the liquid hydrocarbon phase. Furthermore, as can be seen in Fig. 5(b), the pressure increase lead to an increase of the interface thickness in this mixture and to a reduction of the local accumulation on light components, such as $\mathrm{CO}_{2}$. Comparable results were obtained for the binary mixtures and the results are in agreement with those obtained by Miqueu et al. 2005.
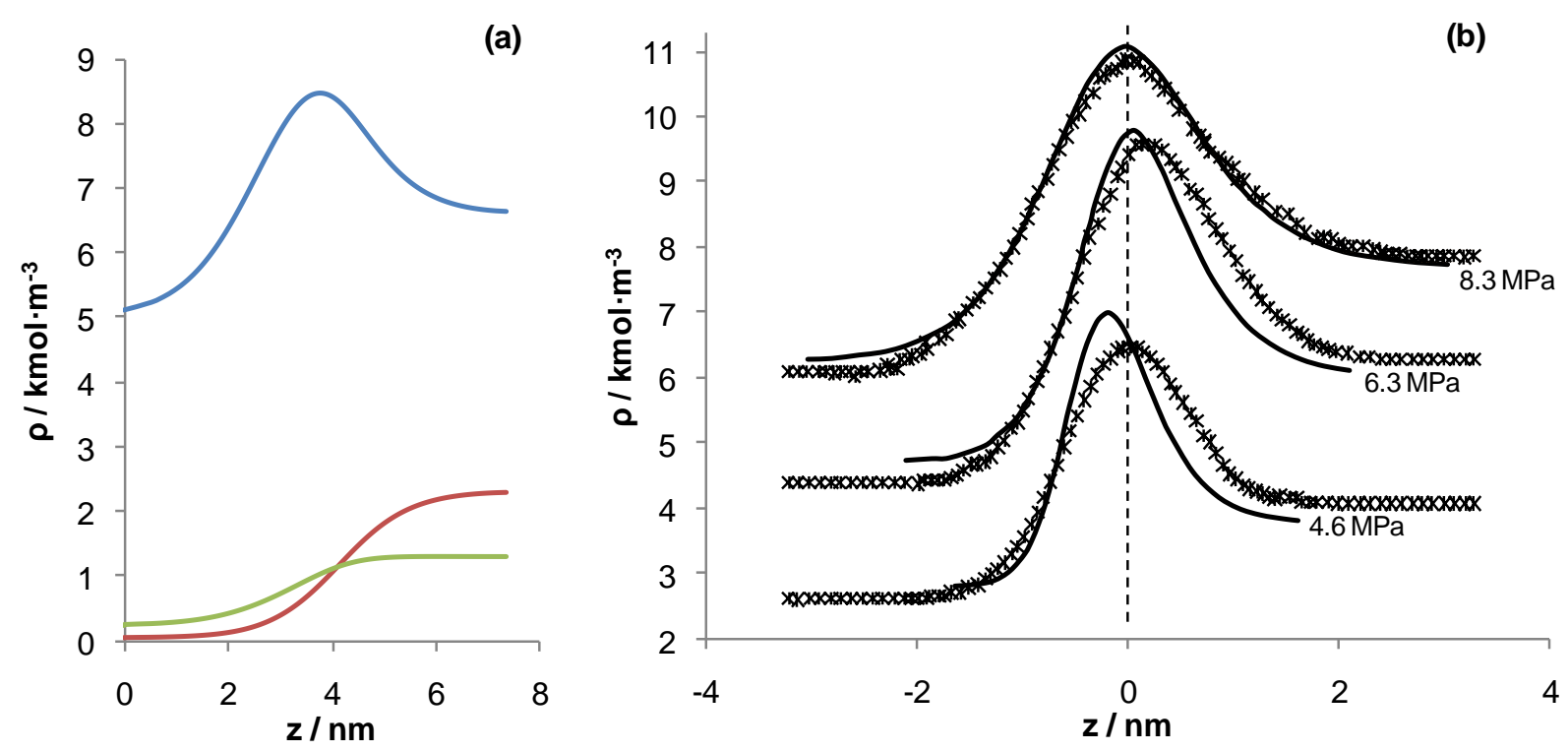

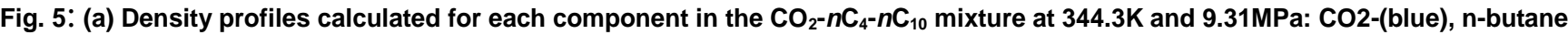
(green) and $\mathrm{n}$-decane (red). Total interface length of $7.36 \mathrm{~nm}$. (b) Density profiles of carbon dioxide calculated for the $\mathrm{CO}_{2}-n \mathrm{C}_{10}$ mixture at 344.3K at different pressures against the results of molecular simulation at same conditions (Müller and Mejía 2009).

\section{Conclusions}

The TRAPP model and the density gradient theory have been combined with the SAFT-VR Mie EoS to model the viscosity and IFT of $\mathrm{CO}_{2}$-rich systems. The low deviations observed to measured density data showed the SAFT-VR Mie EoS good capabilities to describe the equilibrium of the studied systems with $k_{i j}$ presented in this work. Furthermore, by using the computed bulk phase properties, the TRAPP and DGT models were able to predict the viscosity and IFT of $\mathrm{CO}_{2}$-rich mixture with relative low deviations to experimental data, endorsing the capability of the methods for estimating key transport properties of fluids in CCS streams.

\section{References}

Cahn John E., John W Hilliard. 1958. "Free Energy of a Nonuniform System. I. Interfacial Free Energy." The Journal of Chemical Physics 28(2): 258-67. http://dx.doi.org/10.1063/1.1744102.

Carey, B. S. 1979. “The Gradient Theory of Fluid Interfaces.” University of Minnesota. 
Chapoy, Antonin et al. 2013. "Effect of Impurities on Thermophysical Properties and Phase Behaviour of a CO2-Rich System in CCS.” International Journal of Greenhouse Gas Control 19: 92-100. http://dx.doi.org/10.1016/j.ijggc.2013.08.019.

Ely, James F., and H. J. M. Hanley. 1983. "Prediction of Transport Properties. 2. Thermal Conductivity of Pure Fluids and Mixtures." Industrial \& Engineering Chemistry Fundamentals 22(1): 90-97. http://pubs.acs.org/doi/abs/10.1021/i100009a016.

Freeman, K.S.C., and I.R. McDonald. 1973. "Molecular Theory of Surface Tension.” Molecular Physics 26(3): 529-37.

Gubbins, K. C. Mo and K. E. 1976. "Conformal Solution Theory for Viscosity and Thermal Conductivity of Mixtures.” Molecular Physics 31(3): 825-47.

Gubbins, K.E., and C.G. Gray. 1972. "Perturbation Theory for the Angular Pair Correlation Function in Molecular Fluids." Molecular Physics 23(1): 187-91.

Gururaja, G. J., M. a. Tirunarayanan, and Arcot Ramachandran. 1967. "Dynamic Viscosity of Gas Mixtures." Journal of Chemical \& Engineering Data 12(4): 562-67. http://dx.doi.org/10.1021/je60035a024.

H. Knapp, R. Döring, L. Oellrich, U. Plöcker, J.M. Prausnitz, R. Langhorst, S. Zeck. 1982. VI DECHEMA Chemistry Data Series. Vapor-Liquid Equilibria for Mixtures of Low Boiling Substances. Frankfurt.

Hanley, H.J.M., and E.G.D. Cohen. 1976. "Analysis of the Transport Coefficients for Simple Dense Fluids: The Diffusion and Bulk Viscosity Coefficients." Physica A: Statistical Mechanics and its Applications 83(2): 215-32.

Herning, F., and L. Zipperer. 1936. "Calculations of the Viscosity of Technical Gas Mixtures from the Viscosity of Individual Gases.” Gas. and Wasserfach 79: 49-69.

Hobley, A., G. P. Matthews, and A. Townsend. 1989. "The Use of a Novel Capillary Flow Viscometer for the Study of the Argon/carbon Dioxide System." International Journal of Thermophysics 10(6): $1165-79$.

Huber, M. L., and H. J.M. Hanley. 1996. “12. The Corresponding-States Principle: Dense Fluids.” In Transport Properties of Fluids. Their Correlation, Prediction and Estimation, ed. CAMBRIDGE UNIVERSITY PRESS. Cambridge, UK.

Huber, Marcia L., Daniel G. Friend, and James F. Ely. 1992. "Prediction of the Thermal Conductivity of Refrigerants and Refrigerant Mixtures." Fluid Phase Equilibria 80: 249-61.

Kestin, J., H.E. Khalifa, S.T. Ro, and W.A. Wakeham. 1977. "The Viscosity and Diffusion Coefficients of Eighteen Binary Gaseous Systems.” Physica A: Statistical Mechanics and its Applications 88(2): 242-60. http://www.sciencedirect.com/science/article/pii/0378437177900036 (April 29, 2015).

Kestin, J., Y. Kobayashi, and R.T. Wood. 1966. "The Viscosity of Four Binary, Gaseous Mixtures at $20^{\circ}$ and $30^{\circ} \mathrm{C}$." Physica 32(6): 1065-89.

Kestin, J., and W. Leidenfrost. 1959. "The Effect of Pressure on the Viscosity of N2CO2 Mixtures." Physica 25(1-6): 525-36. http://www.sciencedirect.com/science/article/pii/S0031891459954989 (April 29, 2015). 
Kestin, J., and Sung Tack Ro. 1974. "The Viscosity of Nine Binary and Two Ternary Mixtures of Gases at Low Density." Berichte der Bunsengesellschaft für physikalische Chemie 78(1): 20-24. http://onlinelibrary.wiley.com/doi/10.1002/bbpc.19740780104/abstract.

Lafitte, Thomas et al. 2010. "Interfacial Properties of water/CO2: A Comprehensive Description through a Gradient Theory-SAFT-VR Mie Approach.” Journal of Physical Chemistry B 114: 11110-16.

. 2013. "Accurate Statistical Associating Fluid Theory for Chain Molecules Formed from Mie Segments." Journal of Chemical Physics 139.

Li, Hailong et al. 2011. "Viscosities, Thermal Conductivities and Diffusion Coefficients of CO2 Mixtures: Review of Experimental Data and Theoretical Models." International Journal of Greenhouse Gas Control 5(5): 1119-39. http://dx.doi.org/10.1016/j.ijggc.2011.07.009.

Linstrom, P. J., and W. G. Mallard. 2013. "NIST Chemistry WebBook, NIST Standard Reference Database Number 69, National Institute of Standards and Technology, Gaithersburg MD, 20899 (http://webbook.nist.gov)."

Miqueu, C., B. Mendiboure, C. Graciaa, and J. Lachaise. 2004. "Modelling of the Surface Tension of Binary and Ternary Mixtures with the Gradient Theory of Fluid Interfaces." Fluid Phase Equilibria 218(2): 189-203.

Miqueu, Christelle, Bruno Mendiboure, Alain Graciaa, and Jean Lachaise. 2005. "Modeling of the Surface Tension of Multicomponent Mixtures with the Gradient Theory of Fluid Interfaces." Industrial and Engineering Chemistry Research 44(9): 3321-29.

Müller, E a, and a Mejía. 2009. "Interfacial Properties of Selected Binary Mixtures Containing NAlkanes." Fluid Phase Equilibria 282: 68-81. http://www.scopus.com/inward/record.url?eid=2s2.0-67349283338\&partnerID=40\&md5=c1a01c2a9347d69c6b4518402cba06a4.

Nagarajan, Narayana, Khaled a. M. Gasem, and Robert L. Robinson. 1990. "Equilibrium Phase Compositions, Phase Densities, and Interfacial Tensions for Carbon Dioxide + Hydrocarbon Systems. 6. Carbon Dioxide + N-Butane + N-Decane." Journal of Chemical \& Engineering Data 35(7): 228-31. http://pubs.acs.org/doi/abs/10.1021/je00061a002.

Nagarajan, Narayana, and Robert L. Robinson. 1986. "Equilibrium Phase Compositions, Phase Densities, and Interfacial Tensions for Carbon Dioxide + Hydrocarbon Systems. 2. Carbon Dioxide + N-Decane.” Journal of Chemical \& Engineering Data 31(2): 168-71.

Pereira, Luís M.C. et al. 2015. "Study of the Impact of High Temperatures and Pressures on the Equilibrium Densities and Interfacial Tension of the Carbon Dioxide/water System." The Journal of Chemical Thermodynamics. http://linkinghub.elsevier.com/retrieve/pii/S0021961415001378.

Poling, Bruce E., John M. Prausnitz, and John P. O’Connell. 2001. The Properties of Gases and Liquids. Fifth Edit. McGraw-Hill.

R.L., Jack, J.-C. Hsu, and N. Nagarajan. 1985. "Equilibrium Phase Compositions, Phase Densities, and Interfacial Tensions for CO2+Hydrocarbon System. 1. CO2+n-Butane." Journal of Chemical \& Engineering Data: 485-91.

Rowlinson, J. S. 1979. “Translation of J. D. van Der Waals' 'The Thermodynamik Theory of Capillarity under the Hypothesis of a Continuous Variation of Density."” Journal of Statistical Physics 20(2): 197-200. 
Yan, Wei, Farhad Varzandeh, and Erling H. Stenby. 2015. "PVT Modeling of Reservoir Fluids Using PC-SAFT EoS and Soave-BWR EoS." Fluid Phase Equilibria 386: 96-124.

Younglove, B.A., and J. F. Ely. 1987. "Thermophysical Properties of Fluids II. Methane, Ethane, Propane, Isobutane and Normal Butane.” J. Phys. Chem. Ref. Data 16: 577. 